\title{
Opinion
}

\section{A National Math Festival}

Many organizations work to transform public perceptions of mathematics. The AMS's Mathematical Moments, the Carriage House Lectures of the Mathematical Association of America (MAA), the Math Awareness Month sponsored by the Joint Policy Board for Mathematics, the exhibits in the National Museum of Mathematics (MoMath), the films produced by the Mathematical Sciences Research Institute and the YouTube channel Numberphile it supports, the public events hosted by the math institutes, are all substantial contributions. But we're still approached, far too often, with the unabashed announcement: "I never liked/ never was good at/always hated...math."

This is a symptom of a disease with pervasive effects, like the common cold. The condition has a pernicious influence in areas from elementary education to funding for basic research. Fear of mathematics reduces the fulfillment of human potential, increases inequality, and brakes economic growth by blocking the path to fulfilling and valuable careers. It prevents people from taking pleasure in math and from developing their capacity for this deep human endeavor.

In a major new effort, the Mathematical Sciences Research Institute (MSRI) and the Institute for Advanced Study (IAS) are collaborating on the first-ever National Math Festival, a series of events taking place April 16-18, 2015, in Washington, DC. The Festival will not cure the US of its disease, but we hope that it will be noticed widely and begin an influential tradition.

The Festival has so many activities and parts that it is difficult to describe! Here are some highlights:

Math Education and Math Teachers at the Festival: There will be separate events related to federal and state math education policy. On the federal level we will host a congressional briefing stressing the need for teachers' professionalism and (the right kinds of) content knowledge, and we will highlight programs that nurture some of our best math teachers, such as Math for America and the Institute for Advanced Study's Park City Mathematics Institute. On the state level, joining forces with the Council of Chief State School Officers, we will focus on the improving cooperation between the research and K-12 teaching communities, and the progress toward better "college- and career-ready standards." Every state has now adopted such standards, but much work remains.

Basic Research at the Festival: Basic research almost always involves mathematics. There will be a gala dinner, "Act from Thought: The Case for Basic Research" at the Great Hall of the Library of Congress. The chairs of the gala are the wonderful supporters of science and math, Jim and Marilyn Simons, with co-chairs Roger Strauch and Charles Simonyi, who head the Boards of MSRI and

DOI: http://dx.doi.org/10.1090/noti1220
IAS. Among others, Eric Lander (former director of the Human Genome Project) will speak on the importance of mathematics in his work, and NOVA will be on hand to show off clips of its best math-related movies. The gala will bring together influential and powerful people from private and federal organizations that affect funding for research across the sciences.

Children's Books at the Festival: There will be a highprofile announcement of the winners of the first Mathical Book Prizes, "mathy" books for kids from tots to teens: five prizes plus a longer list that we'll distribute to parents, teachers, and librarians. This collaboration between MSRI and the Children's Book Council has a special feature: we are working with First Book, which distributes books at very low prices, to children in need, through a nationwide network (150,000+ nodes).

Come One, Come All! The events above are, by necessity, invitation-only-but a festival wouldn't be a festival without big public events, and there will be plenty! On Saturday, April 18, with the Smithsonian Museums we will offer mathematics applied and mathematics for fun! Hear about Sea Ice, Galaxies, Fireflies, Islamic Art, Drag Racing, Mathematical Magic, Minecraft, and NOVA labs! Ride MoMath's square-wheeled tricycle and visit the other twenty stations of the Math Midway filling the Enid A. Haupt Gardens next to the Smithsonian Castle! Follow the teams of Math Buskers of Guerilla Science! Enjoy Bridges Math+Art exhibition! Play the AMS's game show, "Who Wants to Be a Mathematician?" Compete in the MAA's mathematical scavenger hunt! And much more!

Outside the Beltway: To give the Festival truly national resonance, select science museums around the country will hold a special math event (with ZomeTools, we'll offer a geometric soap bubble kit) on the day or during the week of the Festival-which is also the middle of the JPBM's Math Awareness Month.

Such activity takes time to plan and costs money to publicize and execute. Far-sighted private foundations and individuals will provide resources (nothing is charged to the National Science Foundation). These leaders are the Alfred P. Sloan Foundation, the Carnegie Corporation of New York, the Charles and Lisa Simonyi Fund for Arts and Sciences, Google, the Gordon and Betty Moore Foundation, the Howard Hughes Medical Institute, the Kavli Foundation the Research Corporation, and the Simons Foundation. Our program partners-the Elwyn and Jenny Berlekamp Foundation, MoMath, and NOVA - have brought additional resources.

What if there were a festival and no one knew? Look at the new website, mathfest.org, for more information. Ask your local science museum to participate (information is on the website). Keep up the momentum with local public events. Bring kids to Washington on April 18. We won't cure the common cold-but together we can help spread and deepen the appreciation of math!

-David Eisenbud Director, MSRI de@msri.org 